\title{
Research on the Mode of Cooperative Cultivation of Professional Degree Master in Agriculture by Schools, Enterprises and Local Government and Its Practice
}

\author{
Taking Hunan University of Humanities, Science and Technology as an Example*
}

\author{
Chenzhong Jin \\ Hunan Provincial Collaborative Innovation Center for Field Weeds Control \\ Hunan University of Humanities, Science and Technology \\ Loudi, China 417000
}

Kailing Peng

Hunan Provincial Collaborative Innovation Center for Field Weeds Control

Hunan University of Humanities, Science and Technology Loudi, China 417000

\section{Xiu Liu**}

Hunan Provincial Collaborative Innovation Center for Field Weeds Control

Hunan University of Humanities, Science and Technology Loudi, China 417000

**Corresponding Author

\section{Yihong $\mathrm{Hu}$}

Hunan Provincial Collaborative Innovation Center for Field Weeds Control

Hunan University of Humanities, Science and Technology Loudi, China 417000
Wenxi Jin

Hunan Provincial Collaborative Innovation Center for Field Weeds Control

Hunan University of Humanities, Science and Technology Loudi, China 417000

Taoli Liu

Hunan Provincial Collaborative Innovation Center for Field Weeds Control

Hunan University of Humanities, Science and Technology Loudi, China 417000

\section{Yunyun Zhou}

Hunan Provincial Collaborative Innovation Center for Field Weeds Control

Hunan University of Humanities, Science and Technology Loudi, China 417000

of quality monitoring systems inside and outside campus. Practice has shown that: postgraduate students in agriculture through jointly trained by multiple units can well combine the education and teaching, scientific research and agricultural production, which has significantly improved the application and practical ability of theoretical knowledge of postgraduate students.

Keywords-master in agriculture; cooperative; cultivating mode; base

\section{INTRODUCTION}

The "National Long-term Education Reform and Development Plan Outline (2010-2020)" clearly states that by 2020, China's postgraduate education will shift from mainly cultivating academic talents to training both academic and applied talents. Applied talent training is professional degree master education, which is to cultivate 
high-level application-oriented specialized talents who have strong professional abilities and professional qualities and can creatively engage in practical work to meet the needs of specific social sectors in the society. Hunan University of Humanities, Science and Technology is a local applicationoriented university. Over the years, it has always insisted on serving the local, and transforming and developing into the construction direction of the application-oriented high-level universities. Through cooperation between schools, enterprises and local government, it promotes the development of applied disciplines and fosters the applied professional talents with strong innovation and entrepreneurship ability. [1].

Hunan University of Humanities, Science and Technology has been approved as the pilot construction organization for professional degree postgraduate for "Talent Training Project Serving National Special Needs" since 2011. It has taken the effort of the whole school to carry out postgraduate education for agricultural master degree, and vigorously cultivated high-level applied technological talents in agriculture. In accordance with the needs of the industry, it currently cultivate postgraduates in professional fields of resource utilization and plant protection, agronomy and seed industry, agricultural engineering and information technology, and rural development. The school strictly follows the training requirements for professional degree postgraduates in agriculture, pays great attention to the mentor team, scientific and technological innovation and subject specialty construction platform based on the needs of modern agricultural industry enterprises, and actively explores the talents cultivation model, curriculum system, teaching methods and evaluation methods of the professional degree postgraduates in agriculture to build postgraduate joint training base with companies, industry authorities, and local governments, and constantly improve the postgraduate training quality assurance system, so that it can gradually build the joint postgraduate training base and the talent training mode combining production, study and research based on service requirements to effectively improve the cultivation quality of professional degree postgraduate in the university [2].

\section{JOINTLY ESTABLISHING CULTIVATION OBJECTIVES BASED ON SERVICE NEEDS}

In response to the special needs for high-level application-oriented talents in the agricultural industry, the school invited leaders and experts from the Hunan Provincial Agriculture Commission, the Academy of Agricultural Sciences and related enterprises and institutions within and outside the province to establish the cultivation objective of professional degree postgraduate in agriculture in this university based on the advantages of the agricultural disciplines in our school and the needs of serving the agricultural industry enterprises. The objective is to cultivate "the application-oriented talents in agriculture who can strengthen the cultivation and exercise of the ability for practical application and innovation and entrepreneurship, actively grasp solid professional theoretical knowledge for modern agricultural training, have strong ability to make scientific research and solve practical problems, undertake professional technical or management work in related fields and have good professional qualities and strong innovation and entrepreneurship ability with service demand as the orientation and the combination of production, learning, and research as the approach based on the emphasis on the cultivation of professional knowledge and practical skills.

\section{Jointly DeVEloping PERSONNEl CUltivation PROGRAM CENTERING ON THE TRAINING OBJECTIVES}

In order to ensure that the cultivation program for postgraduate is scientific and reasonable, the school organizes experts to conduct in-depth research on agriculture-related industry companies, accurately grasp the special needs of industry enterprises for the cultivation of high-level applied talents, and invite industry experts to participate in the whole process of development and optimization of training programs. While emphasizing the special characteristics of various majors of agricultural master in this university, the cultivation program focuses on the cultivation of postgraduate service requirements, humanistic qualities, and innovation and entrepreneurship ability. For example, special courses such as "Theories and Practices on the Control of Diseases and Pests of Crop", "Planning and Management of Modern Agriculture Projects" and "Innovation and Entrepreneurship Education" were set up. At the same time, the training program further focuses on strengthening the cultivation and practice of research practice and application and scientific research and professional abilities, and requires that the dissertation topic be selected from the industrial and business issues, and then return to production and application.

\section{COMBINING PRoduction, StUdy AND RESEARCH TO JOINTLY BUILD APPLIED TEACHERS TEAM}

The cultivation of professional degree postgraduate in agricultural master in this university adopts a "tutoring group" guidance system with dual guides and multiple tutors. The school tutors are responsible for the cultivation of postgraduates and the overall guidance of postgraduates. The tutors outside the school are responsible for the practice and research of the joint cultivation base. They guide postgraduate students with the tutors in the school and perform work responsibilities jointly with the first tutor. The tutors inside and outside school will appoint 1-2 practice instructors and form a tutor group to guide graduate students according to the professional knowledge of graduate students and practical research and development. In order to ensure the cultivation quality, and effectively improve the scientific research, practical application, and innovation and entrepreneurial ability of professional degree postgraduate, the school relies on the cooperative cultivation base for postgraduate to jointly build an applied teacher team, which includes: 1) Selecting the full-time teachers who are closely related to agriculture-related enterprise enterprises and have strong business capabilities and certain application results; 2) hiring experts with experience in production and management practices from agriculture-related industries to be external tutors; 3) selecting young tutors to go to 
agriculture-related enterprise or industry sectors for part-time or job-based training, and closely combing cultivation of postgraduates and local agricultural economic development.

\section{JOINTLY CONSTRUCTING CULTIVATION BASE THROUGH COOPERATION BETWEEN SCHOOL, ENTERPRISE AND LOCAL GOVERNMENT}

In order to give full play to the role of postgraduate joint cultivation base in cultivating professional degree postgraduate in agriculture, strengthen the cultivation and training of students' practice, scientific research, and vocational abilities, and improve the quality of postgraduate cultivation, the school attaches great importance to and strengthens cooperation and exchanges between the agricultural industry, enterprises, the government and related universities and scientific research institutes to jointly build postgraduate joint cultivation bases and provide more practical exercise platforms for the cultivation of professional graduate students.

\section{A. Jointly Building Postgraduate Cooperative Cultivation Base with Enterprises}

The school has selected a number of agricultural science and technology, innovative or city-level leading enterprises to build a cooperative agricultural cultivation base for professional degree postgraduate in agriculture. For example, in resource utilization and plant protection fields, it signed a long-term joint postgraduate cultivation agreement with Hunan Haili High-tech Industry Group, Hunan Wuxing Biological Technology Co., Ltd., and Hunan Wanjiafeng Biotechnology Co., Ltd., in agronomy and seed industry with Hunan Longping Seeds Industry Co., Ltd., in rural development, with Hunan Shaw Master Agriculture Development Co., Ltd., and in agricultural engineering and information technology with Changsha Huigu Information Technology Co., Ltd. The companies that signed the agreement covered all areas of the Master in Agriculture in our school, so that every graduate student has the opportunity to study and exercise in the joint cultivation base. In addition, this practical research exercise opportunity provides a good platform for employment between employers and postgraduate. For example, during the practical research in Hunan Longping Seeds Industry Co., Ltd., Zhang Hao, a 2012 postgraduate student, was directly employed by the company due to excellent performance and was quickly promoted to the company's middle management position [3].

\section{B. Jointly Establishing the "Studio for Agriculture, Rural Areas, and Rural Residents" with the Local Grassroots Government}

In response to the special needs for the cultivation of high-level talents of modern agriculture and local economic development, combining the objectives of talent cultivation in various fields, the school closely follow the requirements of modern agriculture and ecological civilization construction in Loudi, successively build a "Studio for agriculture, rural areas, and rural residents" with Xinhua County Organization Department, Caojia, Xinhua County, Shuangjiang county, Louxing District and the Agricultural
Bureau of Shuangfeng County to closely integrate postgraduate student cultivation with local economic development and ecological civilization construction. Relying on the studio, instructors organically connect scientific research topics and graduate cultivation with local economic development and ecological civilization construction; under the guidance of tutors inside and outside the school, students use the knowledge they learned to actively conduct investigations, research, design, data arrangement and feasibility demonstration, and research report writing work to provide suggestions for the regional economic development of local agriculture and the construction of ecological civilization. During the period from 2012 to 2017, relying on the studio, students have actively drafted 22 feasibility studies or consulting projects for local government departments at all levels and related agro-technical promotion departments and enterprises, and completed 10 projects of beautiful rural construction and agricultural park planning.

\section{JOINTLY BUILDING A QUALITY ASSURANCE SYSTEM THROUGH COOPERATION BETWEEN SCHOOL, GOVERNMENT, ENTERPRISES AND TEACHERS}

In order to guarantee the quality of education and cultivation for professional degree postgraduate in agriculture, the school builds a quality assurance system for professional degree postgraduate in agriculture based on the training objectives of postgraduates and personnel training programs with postgraduates cultivation base and instructors inside and outside the school. The quality assurance system mainly includes the following aspects: 1) Bring the classroom teaching monitoring of graduate students into the school supervision management system; 2) In order to ensure the practical research effect of postgraduate students in the joint cultivation base, the school makes clear requirement for the practical research content and practical research objectives of each practical research link in the formulated talents cultivation program, and formulate related management systems and operational mechanisms together with the base; 3) The school has strengthened the quality control of master's degree thesis, focused on strengthening the process management of dissertations, and developed management methods and evaluation criteria for agriculture master dissertation, and provided specific regulations for the topic selection, form, content, quality, achievement evaluation and defense of paper, etc., requiring the tutors in school and outside school and related industry experts to participate in the whole process of professional dissertation such as topics selection, thesis proposal, mid-term assessments, pre-defenses, defenses, and assessments and awards of the degree. The dissertations passed pre-defense are subject to the external review system of "double-blind review". The external review experts must include expert of industry and agricultural research institutes and students who passed blind review can apply for participation of final thesis defense. 


\section{CONCLUSION}

Practice has proved that it is feasible for universities, enterprises, industries, and local governments to jointly cultivate professional degree postgraduate in agriculture. During the cultivation of professional degree postgraduate in agriculture, our school focused on the cultivation of highlevel application-oriented specialized talents in agriculture, organically combined the application of theoretical knowledge, practical ability training, and service demand ability cultivation, well combined the education and teaching, scientific research and agricultural production and integrated graduate education into scientific research and production practices, which fully mobilizes the enthusiasm of universities, enterprises, industries, and local governments.

\section{REFERENCES}

[1] Dong Yuying, Zou Xuejun, Liu Changhong, Bai Rixia. A Study on Deepening the Joint Cultivation Mode of Professional Degree Postgraduate [J]. Journal of Dalian Nationalities University, 2015, 17(5):515-518. 董玉瑛, 邹学军, 刘长宏, 白日霞. 深化专业硕士研究 生校企联合培养模式的研究 $[\mathrm{J}]$. 大连民族学院学报（Journal of Dalian Nationalities University），2015,17(5):515-518.

[2] Chen Yong, Zhou Faming, Peng Jianmin. Exploration and Practice of the "Three-double, Four-module, and Seven-segment" Training Mode for Full-time Professional Degree Postgraduate in Agriculture [J]. Academic Degrees \& Graduate Education, 2017(3):37-43. 陈勇, 周发 明, 彭健民. 全日制农业硕士专业学位研究生 “三双四模块七学 段” 培养模式的探索与实践 [ J ] . 学位与研究生教育, 2017 (3) : 37-43.

[3] W X. Jin, S S.Li, X. Li, Y Y. Zhou, Y H. Hu, X J. Zhang, X S. Tan, T L. Liu, X. Liu, C Z. Jin. Practice for Cultivating Top-level Postgraduates of Agriculture Relied on Collaborative Innovation Platform [C]. Proceedings of the 2017 3rd Conference on Education and Teaching in College and Universities. Paris: Atlantic Press,vol.93,pp185-187. 2017

[4] S S. Li, X. Li, Y Y. Zhou, Y H. Hu, W X. Jin, C Z. Jin. Carrying out Collaborative Innovation to Promote Innovation and Service Ability of Local Colleges and Universities [C]. Proceedings of the 2017 3rd Conference on Education and Teaching in College and Universities. Paris: Atlantic Press,vol.93,pp204-206. 2017. 